\title{
PROMOTING FUN LEARNING IN WRITING THROUGH GAMES
}

\author{
Eka Wulandari \\ State Health Polytechnic of Malang \\ Malang, Indonesia \\ ekawulan09@gmail.com
}

\begin{abstract}
Writing is one of the most difficult skills to master in language learning. It needs lots of hard work and efforts to study this. This condition makes some learners less motivated to study writing. One of the possible ways to avoid this condition is by applying games in teaching and learning process of writing. Games have some positive aspects that make learners studying this skill involuntarily in a fun way. Students will not feel burdened in the process of learning and teachers will not find difficulties to motivate the students for studying. One thing that teachers need to remember is that the teachers must have a full control of the whole process so that the students will not be carried away with the fun only and neglect the learning objective.
\end{abstract}

Keyword: writing, teaching technique, teaching learning process, games, fun

\section{INTRODUCTION}

Language learning especially learning a foreign language is a very hard task to do. Constant effort is required to understand, produce, and manipulate the target language. According to Moursund (2007: 7), there are at least four important ideas in terms of learning any kind of language, they are:

- $\quad$ Learning to learn

- Learning about one's strengths and weaknesses as a learner

- Becoming better at solving challenging problems and accomplishing challenging tasks

- Intrinsic motivation - students being engaged because they want to be engaged

Those principles of learning are very important to be taken care of in order to achieve the best result of learning. Students will not fell burdened in learning a language when these ideas are applied in the process of learning. 


\section{EduLite}

Learning a language also means learning to communicate. Communication means expressing ideas, thoughts, or feelings to others in an oral or written form. In oral communication, we use verbal and non-verbal language to express them through direct communication. Meanwhile, in written communication, we use graphic symbols to express ourselves through indirect communication.

Many people consider that writing is one of the most complicated language skills. Richards \& Renandya (2002: 303) state that writing is the most difficult skill to master because of its difficulties in generating, organizing, and translating ideas into a readable text. When writing a composition, we should think about language aspects for composing a final writing. Some of them are language use (grammar, vocabulary, linkers), punctuation, spelling, and so on.

To make the writing process runs smoothly, some indicators in writing skill must be mastered by a writer. They include the ability to state the main idea in the text, to provide supporting details of the topic, to use appropriate words and phrases to express the idea, to use certain language system (grammar) to make well-formed sentences, to make use of appropriate cohesive devices to create a well-organized text, and to be able to use appropriate mechanics to accomplish the purpose of the speech. Those indicators must be fufilled in a good writing in order to create clarity in a text.

In teaching and learning process, writing takes place as the last of the four skills. This is in line with Alwasilah (2004: 99) who states that "Teaching writing has been considered the most neglected subject in Indonesian schools". On the other hand, time allocation for English teaching is also very limited which makes both the students and teachers consider that writing skill is not really important.

Furthermore, the strategies used are usually very conventional and not interesting. They are not encouraging students to be actively involved in teaching and learning process. Students are only asked to write a paragraph related to a topic given and after that they must submit their work to be evaluated by the teachers. The variation sometimes is only when they 
students are asked to compose a writing based on some series of pictures, cards, or jumbled sentences.

Seeing the facts above, the use of various and interesting strategies may probably be very beneficial to promote fun and fruitful learning in writing. Cahyono \& Widiati (2006: 45) state that the teaching of writing is not an easy task so the teachers are required to know various techniques in teaching it. One of the possible techniques to be used is by applying games in teaching and learning process of English writing.

\section{DISCUSSION}

Why Games?

"Games are effective tools for learning because they offer students a hypothetical environment in which they can explore alternative decisions without the risk of failure. Thought and action are combined into purposeful behavior to accomplish a goal. Playing games teaches us how to strategize, to consider alternatives, and to think flexibly" (Martinson and Chu in TalakKiryk, 2010:4).

The statement above explains why games can be one of the best alternatives for teaching a certain skill in a classroom setting. The use of game does not only reinforce the use of language, but also stimulate creativity, independence thinking, and collaboration among the members of the class. The students are not only actively processing and working with the materials provided but they are actively working with classmates too.

Talak-Kiryk also states that games are fun activities that promote interaction, thinking, learning, and problem solving strategies. Often, games have an aspect that permits the players to produce information in a short period. Some games also require the players to engage in a physical activity and/or complete a mental challenge (2010:4).

The nature of game creates a condition where game can be a very challenging as well as interesting activity to enhance students' motivation to be involved in the teaching and learning process. Games are highly motivating because they are amusing and interesting. They can be used to give practice in 


\section{EduLite}

Journal of English Education, Literature, and Culture

all language skills and used to practice many types of communication (Ersoz, 2000).

The main principle of a language is communication. When playing games, participants are almost forced into communicating in order for the game to work well. The informal setting that the games provide makes students unafraid to communicate, including communicating in a writing form, thus it will create a positive learning environment.

According to Sigurdardottir (2010: 7-9) there are other reasons why games are really suitable to be applied to promote fun learning in language, especially in learning writing. Firstly, they are fun. This condition will activate the passive students and indulge them on their own learning process. Second, games will help to build friendly and positive relationship which will keep the learning environment exciting. Third, by participating in games, students will be exposed to a variety of situations, which is one of the reasons why some people studying language.

Games are also a good way to practice students' fluency in language skills, including writing skill. The activities provided in games will make students more independent in learning and make the shy and unconfident students to open up since the atmosphere will be more relaxing and fun. In the end, it will boost their confidence (Langran and Purcell, 1994: 12-14).

Finally, games can be a good strategy when teaching various subjects because they are very likely to spark interest amongst students. They can be used for students of all ages, and when they are used with other teaching methods they create diversity which is ideal for school work (Ingvar Sigurgeirsson in Sigurdardottir, 2010: 8).

\section{Characteristics of Good Games}

If teachers decide to use games as one of the alternatives for teaching in class, the teachers cannot only consider whether or not the games will be fun and enjoyable for the learners. Teachers must always bear in mind that the games will also be beneficial for the students to develop their language skill. According to Talak-Kiryk (2010), a good game should be: 
- Based on a learning objective, because this game gives the teacher a focus point for the format, skills involved, and material covered. Through the play, the players use previously learned knowledge and skills to acquire new knowledge and enhance their abilities.

- The player of the games should be given control over his own destiny. This will increase the player's motivation, responsibility, and decision making skills

- The game includes doable challenges. They increase the player's determination and drive toward success and completion. Teachers can challenge the students by adding new information or a new situation to which previous knowledge can be applied

- They should be fun, interesting, and motivating. Because of the emotion and excitement involved, the student often forgets that he is learning something. The students will sometimes begin to research information, study harder and practice more so that the next outcome of the game suits his goals. By calling class activities a game even though they are not, the students get excited and have fun without realizing that they are learning something

- The games are based on reality to motivate the players to continue to play the game. The player is able to practice a useful skill without the stress that the real situation may incur. There are chances for multiple practice and redemption. There are supports from peers as well as time to think and react. Situational games allow the players to assume a new identity in a simulated world where they feel comfortable making mistakes and testing hypothesis.

- The games should require interaction. The players should interact with material on a variety of levels and of course with other players, more or less experienced or knowledgeable.

- Games must include everyone, each student should be able to participate as a player in order to effectively develop and promote social interaction, good communication, and a sense of community 


\section{EduLite}

Journal of English Education, Literature, and Culture

The use of Games in Teaching Writing

Writing is a skill that needs to be learned, even in the native language. This makes writing a difficult task to do and even a boring one, especially because usually teachers give writing assignment as homework and the students cannot get direct feedback from the work. Games can be good way to prevent this because they are not only fun, but also gives reason for the students to write.

Nowadays, there are many resources to find suitable games for teaching writing. One of the important things to be considered by the teachers when utilizing games in classroom setting is that the teachers must really take control of the games. Teachers must make sure that the participants will not be too carried away with the fun part only. Also, teachers must be able to select certain games for the students, because one game may be appropriate for a certain class but not for the others.

The rules of the game must also be explained in detail and clearly instructed to all participant s. Teachers' role is to observe and be prepared to help without interrupting the flow of the game that might affect the fluency, which could result in discouraging students from participating. After the game, it is better to have some sort of a follow up activity planned to let the students reflect upon the game and how it turned out (Langran and Purcell in Sigurdardottir, 2010: 10).

To make games effective as one of the teaching technique in language learning, especially in learning writing, some guidance need to be followed. First, the learning objective and procedure must be clear. Then, it is better to team up the students too and make sure that the high capabilities students are divided fairly to all groups, so that they can help each other in team. At last, make sure that teachers are consistent in applying the rules of the games, well prepared with all situations that may arise during the process of the game, and the class environment must be kept in a relaxing and fun atmosphere.

As we know, in the teaching of writing process, a teacher should teach students writing abilities through a sequence of steps. Dealing with the steps, Seow (as quoted by Richards \& Renandya, 2002:315) states "writing process 
as a private activity may be broadly seen as comprising four main stages: planning, drafting, revising, and editing". The process of writing may flow so neatly suitable with flow of the steps above, but often times it also goes forward and backward fashions.

When employing games for teaching writing, the steps for composing a writing product should also be followed through because students are still in the phase of learning and they still need a long process to produce a good final writing product. For example a brainstorming, the students can use it as a pre-writing activity to elicit their prior knowledge before learning (Buehl, 2001: 31 ). In this sequence, the students will be able to explore their knowledge in a fun way, such as by using some pictures as part of the games, using scrabble, using word-game, etc. It is expected that the skill development will be better if the students follow the sequence in writing, even during the game activities.

Some research had also been conducted to find out the effectiveness of games for teaching a language. One of the studies was conducted by Smith (2010), on the students of Chuo University in Tokyo-Japan. He used two-sided card game to teach reported speech for writing. The cards were cut into sets. There were about 20 or 25 cards for each set. He began the lesson by providing examples on the board to activate the students' memories about reported speech. Students are then seated in groups of between three and five members. As they received sets of the two-sided cards, they were directed to place them in a pile with the direct quotation sides facing up. In a predetermined order, a student looked at and read the direct quotation on the top card in the pile. He/she must then say the equivalent reported speech form. Finally, the student turned over the card and checked the answer, which all group members were also shown. The student who had correct answer may keep the card. If not, the card was placed at the bottom of the pile. Then the following student repeated the procedure and once all the cards had been won by the group members, the student with the largest number of cards was declared the winner. This game took place about 20 minutes for each round. During the process, the teacher circulated around the classroom to monitor students' progress and gave some suggestions when students made mistakes. It can be seen that the use of games is one of the best ways to introduce or 


\section{EduLite}

Journal of English Education, Literature, and Culture

reinforce proper use of grammatical structures to be applied in writing. This activity turned to be an effective and enjoyable way for students to master English writing skill.

Another study was conducted by Diana (2010) on the use of games for teaching English to the third graders of TOP elementary school in SukoharjoCentral Java. It was held in January-March 2010. The writer used some types of games to teach writing, such as by using colored pictures, matching pictures with some words or sentences, crossword puzzle, etc. She concluded that the using of games in English teaching to young learners can make the students more interested in learning the material and the teacher doesn't need to explain too many materials to the students.

Finally, Kiryk (2010) had also conducted a study which reviewed the value of using games in classroom setting. It focused on the educational benefits as well as on recommendations how to incorporate games into a learning environment. The games were experimented in a Spanish classroom in an American high school with teenagers ages fourteen to eighteen. The result of the research showed that games may provide students, especially teenagers, a situation to learn without barriers created by social norms, and mundane routines or performances.

As conclusion, it can be suggested that games can encourage language production and also promote social interaction in a playful and fun way that makes language learners feel more confident to communicate in the target language. This condition will create better learning atmosphere for students to study the language, which in the end will bring optimum outcomes for language learning.

\section{Let's Play the Game!}

The games described in this section are compiled from many resources. All of them are supposed to help students learning writing in a fun way. They can be applied for some levels of students, ranging from elementary to advanced students. You may use them in your class with some adjustments based on the class conditions. 


\section{The Newlywed Game}

Level: $\quad$ Intermediate and Advanced

Materials: Player: a piece of paper and writing utensils

Teacher: a variety of questions of a personal nature

Procedure: - Students, in groups of two, ask each other relatively personal questions. For example: When is your birthday? What is your favorite color? With whom do you live? etc.

- The groups now arrange their desks so that they are seated back to back so they cannot communicate with each other. Each player should have a piece of paper and writing utensil.

- The teacher asks random questions, that the students were not aware of beforehand.

- One student writes down his answers to the question and the other writes down what he thinks his partner will say.

- As the group go over answers of the pairs, and then repeat the process with the pairs changing roles.

- The goal is for the pairs to match answers and develop connections. The pair with the most matching answers wins.

Some of the possible questions:

- What is your favorite color?

- Who is your favorite actor?

- When is your birthday?

- What is your favorite subject?

- Where do you like to go for holidays? etc.

\section{Memory}

Level: $\quad$ Beginner to Advanced

Material: Index card

Procedure: - Have the students create matching pairs.

- The most common set up would be to have a word on one card, and its corresponding picture on the other.

- Turn the cards face down, and rearrange them so that no pairs are near each other. 


\section{EduLite}

Journal of English Education, Literature, and Culture

- Each student takes a turn attempting to find the match.

- When a match is made, then he or she gets to go again.

- The teacher can ask the students to do this step for some turns to collect cards.

- Then, they must choose cards randomly and have to use them in a logical sentence or story

- The pair that can create most logical interesting sentence/story wins.

\section{Who am I}

Level: $\quad$ Intermediate to Advanced

Materials: Pens and paper

Procedures: - Give each student a piece of paper.

- Have them write a short paragraph about themselves.

- Fold the paper in half and collect.

- Redistribute the paper.

- Have the students read the paragraph and guess who wrote them

\section{Describe and Draw a Picture}

Level: $\quad$ Intermediate to Advanced

Materials: Paper, writing utensils, and other pictures

Procedures: $\quad$ - Students should work in pairs.

- One member of the pair should have a blank piece of paper and writing utensils.

- The other member should be given a picture to describe.

- The partner with a picture then starts to describe for his/her partner. All the while, the other member can ask or give clarifying information based on how the description is going.

- The pair with the most correct description wins.

\section{Truth or Lie?}

Level: Intermediate to Advanced

Materials: Paper and pencil 
Wulandari, Promoting Fun Learning in Writing through Games

Procedures: - Distribute a paper and pencil to each student.

- Each student should their name on the paper.

- Next, he/she should write three sentences about him/herself. Two of them should be true and one should be a lie.

- Collect the sentences.

- Read the sentences to the class and have them guess which one is a lie.

\section{Relay Games}

Level: $\quad$ Beginner to Advanced

Materials: $\quad$ Paper and marker

Procedures: - Divide the students in pairs

- Ask each pair to create a sentence in a paper

- Put the paper in a spot in the room.

- Have other pairs to add a sentence to continue the one sentence. They must do it in turns.

- The final sentence must be logical.

- Make it challenging by allowing certain pair to add certain parts of speech.

\section{Sentence Collage}

Level: $\quad$ Lower to Intermediate

Materials: Strips of paper

Procedures: - Take a sentence with a structure you want to build into.

- Copy each word of the sentence onto separate strips of paper.

- Ask one student to draw a picture related to sentence you have created.

- Split the class into groups of five to seven - have one group at the board and the other groups round the walls of the classroom. Give each group a set of words in the sentence (shuffled), two to four words to each student, and ask them to find a sentence to which all words fit grammatically and intelligibly.

- Do not interfere or help - let the students argue among themselves where the words should go. They may well end up with sentences that different than the original one, which is fine. 


\section{My Sentences - Your Paragraph}

Level: Intermediate

Materials: None

Procedures: - Ask the class to tell you all the linking words they know. You might start them off by suggesting and, but. Build up a list on the board. There will be some you will have to explain/translate for people who do not know them, or are not sure they know them.

- Write up on the board five open, general sentences around a theme, e.g.:

a. Teenagers have never been pensioners.

b. In old age you may want to be close to your relatives.

c. I don't like thinking about ageing.

d. Some young people feel guilty about old people.

e. At times, old people want to be independent.

- Ask the students to work on their own and put the above sentences in any order they want, linking them into a two or three sentence paragraph. They may add linking words and further linking clauses or sentences to make a full paragraph. While this is going on, go round and help students who are getting linking words wrong.

- Ask the students to stick their paragraphs up on the walls of the classroom; they then go round and read each other's.

\section{With Your Back to the Class}

Level: $\quad$ Elementary to Intermediate

Materials: None

Procedures: - Write three words at the top of the board, e.g. explosion, manager, roof. Tell the students these are the three keywords in a story you have in your head (you may create any story you want). They are to ask YES/NO questions to try to discover what happened in the story. They are to come up and write these questions on the board, as the exercise is going to be entirely silent.

- Sit with your back to the class. Explain that as soon as a student has written a question on the board. You will give a THUMBS UP signal if it is correct and a THUMBS DOWN signal if it is wrong. If 
Wulandari, Promoting Fun Learning in Writing through Games

the signal is thumbs down, the writer of the question and the class have to try and correct the mistake.

- Once the sentence on the board is correct, you will either nod your head vigorously to indicate YES to the question, or shake it from side to side to indicate NO to the question.

- During the silent, written questioning, you may want to give the class another clue - write an extra keyword on the board.

- Possible story: "The manager of a Sports Center woke up one morning to find there had been a very heavy fall of snow. He realized that the flat roof of the Center was in danger of collapsing. He got on the roof to shove off some of the snow. His extra weight made the roof cave in causing the air inside the hall to compress and blow the doors out, hence the explosion".

\section{Words into Stories}

Level: $\quad$ Elementary to Intermediate

Materials: None

Procedures: - Each student in a group secretly writes down one word.

- The group, the same team, or another team then has to put these words together to make a story.

- The story can be very simple, but the words should fit into it somehow.

- The students may also write a number of words and put them into a bag or box.

- They then draw out a certain number of words and make a story.

- They can either make the story word by word with each student drawing out a word and making the story longer, or they can draw out a number of words and arrange them in order to make a story

\section{CONCLUSION}

From the discussion above, we can conclude that games are indeed can be a very useful method for teaching writing in English. Games will help to avoid students from boredom and make them become engaged optimally in 


\section{Edulite}

Journal of English Education, Literature, and Culture

teaching and learning process. Writing as one of the most difficult skills to learn in language learning will become more fun and enjoyable to learn. But still, teachers should have clear instruction, consistent, and have full control of the game process, so that students will not be carried away with the fun and neglecting the objective of doing the game.

The focus of learning a language is to learn to communicate. So, the games employed in the classroom must have a clear objective on developing communication skill, in this case, the writing skill. Teachers should be careful in choosing the game that suits with the objective and the type of learners faced by the teacher.

Last but not least, in this article I have compiled some of the possible games that can be applied in classroom setting to help teachers making the class situation challenging but fun. But we should also remember that the effectiveness of the games applied in the class also depends on the teacher who will use them in class because they are the ones who know the situation of the class and what types of students he/she has. The most important thing to consider is what will be the end result of the games applied and how it will affect the learning outcomes of the students.

\section{REFERENCES}

Alwasilah, A.C. 2004. Improving Writing Skill through Collaborative Writing. In B.Y. Cahyono \& U. Widiati. (Eds.), The Tapestry of English Language Teaching and Learning in Indonesia, (pg. 99-108). Malang: State University of Malang Press.

Buehl, D. 2001. Classroom Strategies for Interactive Learning. Madison: International Reading Association.

Cahyono, B.Y. \& Widiati, U. 2006. The Teaching of EFL Writing in the Indonesian Context. The State of Art. Jurnal Ilmu Pendidikan, 13 (3): 139-150.

Diana, Nova Pravita Rus. 2010. The Advantages and Disadvantages of Using Games in Teaching Vocabulary to the Third Graders of Top School Elementary School. Unpublished Thesis. Surakarta: Sebelas Maret University

Ersoz, Aydan. 2000. Six Games for AFL/ESL Classroom. The Internet TESL Journal, Vol. VI No. 6 (June). 
Wulandari, Promoting Fun Learning in Writing through Games

Langran, John and Purcell, Sue. 1994. "Language Games and Activities". Netword 2. Teaching Languages to Adults. London: Center for Information on Language.

Moursund, Dave. 2007. Introduction in Using Games for Education: a Guide for Teachers and Parents. University of Oregon: Teacher of EducationCollege of Education.

Richards, J.C. \& Renandya, W.A. 2002. Methodology in Language Teaching: An Anthology of Current Practice. Cambridge: Cambridge University Press

Rinvolucri, Mario. 1995. Grammar Games: Cognitive, Affective, and Drama Activities for EFL Students. New York: Cambridge University Press.

Sigurdardottir, Sigridurdogg. 2010. The Use of Games in the Language Classroom. Iceland: Sigillum Universitatis Islandiae.

Smith, David. 2010. Teaching Reported Speech for Writing: a Game Approach. The Internet TESL Journal, Vol. XVI, No. 3, March.

Talak-Kiryk, Amy. 2010. A Thesis: Using Games in a Foreign Language Classroom. Vermont: SIT Graduate Institute. 